\title{
Endothelial Progenitor Cells Dysfunction in Diabetes Mellitus
}

\author{
Alexander E. Berezin \\ Professor, MD, PhD, Consultant of Therapeutic Unit, Internal Medicine Department, State Medical \\ University of Zaporozhye, Mayakovsky av., Zaporozhye, Ukraine. \\ dr_berezin@mail.ru; aeberezin@gmail.com
}

\begin{abstract}
Diabetes mellitus (DM) is considered a leading cause of premature cardiovascular (CV) mortality and morbidity in general population and in individuals with known CV disease. Recent animal and clinical studies have shown that reduced number and weak function of endothelial progenitor cells (EPCs) may not only indicate to higher CV risk, but contribute to the impaired heart and vessels reparation in patients with DM. Moreover, EPCs having a protective impact on the vasculature may mediate the functioning of other organs and systems. Therefore, EPCs dysfunction is probably promising target for DM treatment strategy, while the role of restoring of EPCs number and functionality in CV risk diminish and reduce of DM-related complications is not fully clear. The aim of the review is summary of knowledge regarding endothelial progenitor cells (EPCS) dysfunction in DM patients.
\end{abstract}

Keywords: diabetes mellitus; endothelial progenitor cells,

\section{INTRODUCTION}

Diabetes mellitus (DM) is a worldwide epidemic metabolic disease associated with increased cardiovascular (CV) complications, premature $\mathrm{CV}$ death, and a higher incidence of disability leading to social and economic burden [1]. DM was found as the important cause of atherosclerosis, coronary artery disease, chronic renal disease, and heart failure [2-5]. Basic studies have exhibited evidence regarding the innate complex mechanisms underlying changes that occur in the vasculature during $\mathrm{DM}$ and lead to $\mathrm{CV}$ risk associated with macrovascular and microvascular complications of DM. There are several biochemical, hemodynamic and endocrine mechanisms with a preponderant initial role in DM-related vascular dysfunction. It is suggested that hyperglycemia, lipotoxicity and hypoxia are essential factors contributing in the microvascular inflammation, endothelial dysfunction and endothelium injury [6]. On this way, worsening of intracellular signaling, activation of alternate polyol pathways, increment of growth factors (growth-differentiation factor-15, vascular endothelial growth factor - VEGF), and accumulation of advanced glycation end products (AGE), activation of protein kinase $\mathrm{C}$ (PKC), activation of the renin-angiotensin-aldosterone system (RAAS), inducting of oxidative stress and apoptosis, decreased nitric oxide (NO) bioavailability, and leukostasis were found an independent causes of weakened endothelium repair ability and worsening of endothelial integrity [7-10]. Finally, co-acting endothelial injury, incompetence in vascular reparation mechanisms and existing co-morbidities (i.e. hypertension, obesity, hyperuricemia, dyslipidemia) may lead to endothelial dysfunction, acceleration of atherosclerosis, senescence, thereby they may negatively influence on CV risk and development of CV disease [11-13]. The key role in the endothelial repair, vasculogenesis, neovascularization and attenuation of vasculature function plays endothelial progenitor cells (EPCs) derived from bone marrow and peripheral blood [14]. In contrast to recently proposed local "response to endothelium injury hypothesis" EPCs, which are mobilized or released into systemic circulation in response to specific stimuli, contribute vessel formation and endothelium reparation directly and through involvement of several paracrine mechanisms $[15,16]$. Low number and weak functionality of EPC were found in subjects with DM 1 and 2 types, as well as in patients with prediabetes including metabolic syndrome, obesity and insulin resistance [17, 18]. In this context, EPCs' dysfunction is considered a marker of CV risk in general population and in subjects with known DM, as well as a cause of DM-related complications [19]. The aim of the review is summary of knowledge regarding endothelial progenitor cell dysfunction in DM patients. 


\section{Determination of Endothelial Progenitor Cells}

There are some controversies regarding the definition, origin, determination and isolation of EPCs. Indeed, the definition of EPCs is not standardized completely [20]. On head EPCs were defined as cells positively labeled with both hematopoietic stem cells (CD34) and endothelial cell markers predominantly VEGF receptor-2 (VEGFR2) cumulatively [21]. VEGFR2 is kinase insert domain receptor (KDR) and in follow term "KDR-positive precursor" as a one of important determinations of EPCs has been remained to use optionally.

The later an expression of other hematopoietic stem cells (CD133 aslo known as AC133) markers and endothelial markers (i.e., platelet-endothelial cell adhesion molecule known as CD31, VE-cadherin also known as CD 144, caveolin-1, von Willebrand factor, and endothelial NO synthase) on the surface of EPCs was determined [22-26]. Interestingly, several subsets of EPCs may exhibit "nonclassical" phenotype expressing CD45, Tei2 and Flt-1 markers [27]. However, it has been found that subset of circulating CD34(+) cells expressing VEGFR2 and CD133 was a phenotypically and functionally distinct population of circulating EPCs that may influence on the reparation and angiogenesis [28].

In the pioneer investigation provided by Hur J et al (2004) [23] two types of EPCs labelled as early EPCs and late outgrowth EPCs and received from the same source were identified. They have expressed different level of CD144, Flt-1, KDR (VEGFR2), and CD45 markers. Late outgrowths EPCs produced more nitric oxide, incorporated more into human umbilical vein ECs monolayer, and are able to better form capillary tube than early EPC. However, early EPC secreted more angiogenic cytokines (VEGF and interleukin-8) than late EPC at culture. Therefore, early EPCs intervened in the monolayer of human umbilical vein endothelial cells (HUVEC), but more late EPCs were incorporated to HUVEC [23]. These suggest that two types of EPC might have different roles in neovasculogenesis and neovascularizetion. Thus, by now to help classify EPCs, they have used their ability to differentiate into circulating angiogenic cells (referred as early EPCs) and forming endothelial colony cells (referred as late outgrowth EPCs) [28].

Recently investigations have shown that other population of EPCs distinguished from BM-EPCs and was found in the circulation and / or in the tissue (so called "tissue residential EPCs") may express monocyte marker CD14, together with CD34 or VEGFR2 [29, 30]. Interestingly, early EPCs are able to express several monocyte markers, i.e. CD14, CD11b, CD11c, on their surface. Contrary, the populations of late outgrowth EPCs were determined as predominantly CD14-negative and they have usually expressed markers of mature endothelial cells [31]. This "non-classical" phenotype of EPCs has associated with vascular protective capacity and may differentiate into mature endothelial cells under influence of microenvironment in the presence of special growth factors (e.g., VEGF, fibroblast growth factor) and paracrine regulators [32,33].

Despite the exact mechanisms by which EPCs provide cardiovascular protection are unknown [20], both populations of EPCs (early and late outgrowth) are probably to be equal in their ability to produce angiopoetic capacities [34]. However, there is evidence regarding early EPCs could be superior than late outgrowth EPCs to secret angiopoetic cytokines in vitro [23]. Overall, the controversies in heterogeneity of EPCs and their functional capabilities remain uncertain yet.

\section{Definition of Endothelial Progenitor Cell Dysfunction}

Because of EPCs originated from bone marrow cells and peripheral blood cells maintenance endothelial homoeostasis and attenuate the process of angiogenesis and neovascularization, a lot of investigators thought the EPCs as a component of endogenous repair system. Moreover, EPCs having a protective impact on the vasculature may mediate the functioning of other organs and systems [19, 20, 22, 29]. In this context, dysfunction of EPCs defined as wear EPCs functionality (i.e., reduced ability to proliferation, differentiation, adhesion, migration, incorporation into tubular structures, and survival) and / or lowering EPCs' count in the circulation might be a critical step in the initiation of any cause-related vasculopaty that links etiological factors, co-morbidities, aging and clinical events [35]. Nevertheless, EPCs dysfunction may be a useful predictive tool for evaluating the risk of death in general population and among subjects with known CV and metabolic disease including DM. 


\section{The Molecular Mechanisms of Progenitor Endothelial Cell Dysfunction In DIABETES MELLITUS}

Alteration of structure and function of the EPCs has identified in type 1 and type 2 DM [20]. The mechanisms underlying EPC reduction in diabetes predominantly include weak bone marrow mobilization, decreased proliferation, and shortened survival [36]. It has suggested that in DM glucose toxicity, lipid toxicity and reactive oxidative species (ROS) via enhancing inflammation may regulate proliferation BM-EPCs $[6,9,20]$. The key mechanism of this response is the activation of matrix metalloproteinase-9 (MMP-9) through intracellular signal systems, i.e. Akt / STAT and nitric oxide dependent signaling [37]. Maturation and mobbing of the BM-EPCs are under control of growth factors, such as chemokine stromal cell-derived factor-1 (SDF-1), VEGF, granulocyte colonystimulating factor (G-CSF), and alpha-chemokine that binds to G-protein-coupled CXCR4 [38, 39]. Lataillade JJ et al (2000) reported that SDF-1 may stimulate the growth of EPCs' colonies, chemotaxis and cell expansion [39]. Nevertheless, SDF-1 is able to improve survival of the EPCs in culture through suppression of their apoptosis [40]. SDF-1 exerts pleiotropic effects regulating chemoattraction and adhesion of EPCs in CXCR4-dependend mechanisms playing an essential role in the trafficking of EPCs in various tissue including heart and vasculature [41]. It is importantly that SDF-1 gene expression in EPCs and endothelial cells is regulated by the transcription factor hypoxiainducible factor-1 (HIF-1), which is under control of reduced oxygen tension in the tissues [42]. VEGF has exhibited autocrine action in EPCs suppressing apoptosis and protect a survival effect [43]. GM-CSF may accelerate re-endotheliazation and reduce microvascular inflammation through mobbing of EPCs [44]. There is evidence that "residence" EPCs originated from myeloid cells could trans-differentiate into endothelial cells in the same manner [34].

DM is characterized reduced expression of angiopoetic factors (SDF-1, VEGF, G-CSF, CXCR4) in heart and vasculature [18]. Moreover, differentiation and mobbing of EPCs after ischemia-reperfusion injury in DM is defective [46]. The initial role in these processes belongs to over-production of ROS, decreased superoxide dismutase activity, and probably SDF-1 genotype polymorphism [18, 42, 47], whereas epigenetic changes in EPCs are considered an important mechanism, which links hyperglycemia, lipid toxicity and metabolic memory $[6,9,48]$. Finally, weak functionality of EPCs in type 1 and type $2 \mathrm{DM}$ is resulting mutual related molecular mechanisms affected cellular signal systems, paracrine regulation and epigenetic modification. Therefore, poor differentiation, mobbing and proliferation of BM-EPCs and PB-EPCs lead to decreased circulating pool of primitive cells and worsening reparative capability [40].

\section{Endothelial Progenitor Cells and CV Risk}

Reduced number and weak functionality of circulating EPCs have been demonstrated sufficiently correlation with vascular endothelial dysfunction and independently association with both traditional (aging, hypertension, hypercholesterolaemia, smoking, diabetes, C-reactive protein level) and nontraditional (insulin resistance, adipocyte dysfunction) CV risk factors, Framingham risk factor score [49-51], as well as frequency of major CV events, revascularization, hospitalization rate and death from CV causes [52-54]. Most importantly, EPCs isolated from peripheral blood of the patients with known CAD have exhibited an impaired migratory and weak proliferative response [50], which have confirmed being of "EPC impaired phenotypes" pre-existing in subjects with CV risk factors prior established CV disease $[55,56]$. However, the circulating level of EPCs in patients with established higher CV risk is very variable and does not fully correlate with number of CV risk factors $[57,58]$, although number of BM-EPCs has closely predicted asymptomatic atherosclerosis $[59,60]$ and CV disease [61]. One found that lowered number of circulating EPCs originated from bone marrow have accompanied with hypercholesterolemia-induced expression of pro-inflammatory molecules by the vessel wall [62]. Additionally, the level of circulating CD34+KDR+ EPCs may help to identify patients at increased CV risk [55].

However, there are controversies regarding number and colony-forming ability of circulating BMEPCs and PB-EPCs in individuals with established CV disease and metabolic disease, i.e. DM, metabolic syndrome, obesity. The first controversial reflects disproportion between circulating level of EPCs depending stage of CV disease. To update our knowledge, at the early stage of CV disease especially in patients with asymptomatic atherosclerosis, moderated increase of the EPCs' count in circulation was found [63]. In contrast, lowered level of EPCs might clarify a severity of 
atherosclerosis or DM-related vasculopathy $[64,65]$. The next controversial relates to the level and functionality of EPCs in subjects with obese, metabolic syndrome and DM. Interestingly, at the early stage of metabolically inactive obesity ("not fully" metabolic syndrome) BM-EPCs number may increase and an ability of primitive cells to mobbing, differentiation and colony forming might be not distinguished healthy individuals [66]. In contrast, development of insulin resistance, metabolic syndrome and type 2 DM has closely associated with weak ability of EPCs to mobbing, and the lowered level of circulating EPCs was determined [67]. In contrast, Asnaghi V et al (2006) [68] have reported that clonogenic potential of circulating EPCs in patients with type 1 DM may increase. Finally, heterogeneity of EPCs and the variable changes in the EPCs' phenotypes at the different stages of CV disease and development of DM are limiting factors to determine the predictive value of count and functionality of EPCs in CV risk calculation.

\section{THE CONCEPT OF IMPAIRED CARDIAC AND VESSEL REPARATION IN DIABETES: Role OF EPCS}

EPCs are involved in the homeostasis of the heart and vessels, and their exhaustion or dysfunction may accelerate the course of DM-related CV complications. Because uncommitted progenitor cells can differentiate toward the several phenotypes (i.e. endothelial cell phenotype), it is possible that a broader derangement of immature EPCs predisposes to CV complications in DM [69]. Whether weak functionality and / or lower number of EPCs exist prior to both CV risk and established CV / metabolic diseases or they appear resulting in CV risk factors' influence on epigenetic mechanisms of immature progenitors is not fully clear. However, an ability of BM-EPCs and PB-EPCs to restore of structure and function of cardiac and vessels in DM is sufficiently impaired [70]. There is evidence regarding potent possibilities to improve the EPCs' capacity using various methods, i.e. aerobic exercise, lipid lowering drugs, ACE inhibitors, calcium channel blockers, antidiabetic drugs including metformin, sitagliptin [71-75]. Several mechanisms are involved in the attenuation of EPCs functionality by mentioned above approaches, i.e. increase of NO production via enhancing phosphorylated-AMP-activated protein kinase and phosphorylated-eNOS, down-regulation of high mobility group box-1 and AkT / STAT signaling leading to oxidative stress suppression, attenuation of DNA / histone methylation, inhibition of progenitor cells' apoptosis and NETosis through suppression of proprotein convertase subtilisin/kexin type 9 and Dll4/Notch signaling pathway [7678]. Subsequently, improving function of EPCs in DM appears to be under control and the prevention of CV complication development could be associated with restoring of EPCs-dependent repair mechanisms.

Thus, the EPCs may enhance the balance between heart and vascular injury and repair that is critical for the maintenance of cardiac remodeling, heart function, intimal integrity, endothelial function, and prevention of CV complications [79]. All these findings elucidate that EPCs dysfunction could be an alternative therapeutic target to promoting heart and vessels repair in patients with DM. Despite these promising results received in animal and clinical studies, there is not clear whether the EPCs functionality could be restore completely and the circulating number of EPCs would be achieved the level of healthy individuals. By now, the results of the recently performed investigations have shown that EPCs dysfunction in DM remains to be unresolved yet. Probably, there is required more investigations to explain whether EPCs-dependent mechanisms of tissue repair could be exhibited clinically significant relevance or they are an attribute of nonspecific influence of recently known therapeutic approaches.

In conclusion, reduced number and weak function of EPCs may not only indicate to higher CV risk, but contribute to the impaired heart and vessels reparation in patients with DM. EPCs dysfunction is probably promising target for DM treatment strategy, while the role of restoring of EPCs number and functionality in $\mathrm{CV}$ risk diminish and reduce of DM-related complications requires more investigations.

\section{Abbreviations}

AGE - advanced glycation end products

BM-EPCs - bone marrow-derived endothelial progenitor cells

CAD - coronary artery disease

$\mathrm{CV}$ - cardiovascular 
$\mathrm{DM}$ - diabetes mellitus

EPCs - endothelial progenitor cells

G-CSF - granulocyte colony-stimulating factor

HIF-1 - hypoxia-inducible factor-1 (

HUVEC - human umbilical vein endothelial cells

MMPs - metalloproteinases

NADPH - nicotinamide-adenine dinucleotide phosphate

$\mathrm{NO}$ - nitric oxide

PB-EPCs - peripheral blood-derived endothelial progenitor cells

$\mathrm{PKC}$ - activation of protein kinase $\mathrm{C}$

RAAS - the renin-angiotensin-aldosterone system

ROS - reactive oxidative species

SDF-1 - chemokine stromal cell-derived factor-1

T2DM - type 2 diabetes mellitus

VEGF - vascular endothelial growth factor

\section{REFERENCES}

[1] Stöckl D, Rückert-Eheberg IM, Heier M, Peters A, Schipf S, Krabbe C, et al.. Regional Variability of Lifestyle Factors and Hypertension with Prediabetes and Newly Diagnosed Type 2 Diabetes Mellitus: The Population-Based KORA-F4 and SHIP-TREND Studies in Germany. PLoS One. 2016;11(6):e0156736.

[2] Busch M, Nadal J, Schmid M, Paul K, Titze S, Hübner S, et al; GCKD Study Investigators. Glycaemic control and antidiabetic therapy in patients with diabetes mellitus and chronic kidney disease - cross-sectional data from the German Chronic Kidney Disease (GCKD) cohort. BMC Nephrol. 2016; 17(1):59.

[3] Kamceva G, Vavlukis M, Kitanoski D, Kedev S. Newly Diagnosed Diabetes and Stress Glycaemia and Its' Association with Acute Coronary Syndrome. Open Access Maced J Med Sci. 2015; 3(4):607-12.

[4] Abdullatef WK, Al-Aqeedi RF, Dabdoob W, Hajar HA, Bener A, Gehani AA. Prevalence of Unrecognized Diabetes Mellitus in Patients admitted with Acute Coronary Syndrome. Angiology. 2013; 64(1):26-30.

[5] Capes SE, Hunt D, Malmberg K, Pathak P, Gerstein HC. Stress hyperglycemia and increased risk of death after myocardial infarction in patients with and without diabetes: a systematic overview. Lancet. 2000; 355:773-78.

[6] Berezin A. "Impaired Phenotype" of Endothelial Cell-Derived Microparticles: Causality Factor Contributed the "Vascular Competence" in Diabetes and Metabolic Syndrome? Diabetes Res Treat Open Access.2016; 3: 133-136

[7] Capitão M, Soares R. Angiogenesis and Inflammation Crosstalk in Diabetic Retinopathy. J Cell Biochem. 2016. doi: 10.1002/jcb.25575. [Epub ahead of print]

[8] Berezin A. "Impaired immune phenotype" of endothelial cell-derived microparticles: the missed link between diabetes-related states and cardiovascular complications? Journal of Data Mining in Genomics \& Proteomics. 2016; 7(2): 195-197

[9] Berezin A. Metabolic memory phenomenon in diabetes mellitus: achieving and perspectives. Diabetes \& Metabolic Syndrome: Clinical Research \& Reviews. 2016; [Epub ahead of print] DOI: 10.1016/j.dsx.2016.03.016.

[10] Ogita H, Liao J. Endothelial function and oxidative stress. Endothelium. 2004;44:248-252

[11] Cai H, Harrison DG. Endothelial dysfunction in cardiovascular diseases: The role of oxidant stress. Circ Res. 2000; 87: 840-844.

[12] Berezin A, Kremzer A, Berezina T, Martovotskaya Yu, Gromenko O. Pattern of endothelial progenitor cells and apoptotic endothelial cell-derived microparticles in chronic heart failure 
patients with preserved and reduced left ventricular ejection fraction. EBioMedicine. 2016; 4: 86-94 Doi: 10.1016/j.ebiom.2016.01.018.

[13] Berezin AE, Kremzer AA, Martovitskaya YV, Samura TA, Berezina TA. Serum Uric Acid Predicts Declining of Circulating Proangiogenic Mononuclear Progenitor Cells in Chronic Heart Failure Patients. J Cardiovasc Thorac Res, 2014;6(3):153-62 doi: 10.5681/jcvtr.2014.0XX

[14] Berezin AE, Kremzer AA. Signature of circulating endothelial-derived progenitor cells in patients with metabolic syndrome and diabetes mellitus. Biological Markers and Guided Therapy. 2015; 2 (1): 113-135.

[15] Berezin AE, Kremzer AA. The impact of low-grading inflammation on circulating endothelialderived progenitor cells in patients with metabolic syndrome and diabetes mellitus. Journal of Endocrinology and Diabetes. 2015; 2 (3): 8-16.

[16] Berezin AE, Kremzer AA. Circulating endothelial progenitor cells as markers for severity of ischemic chronic heart failure. J Card Fail. 2014; 20 (6): 438-447.

[17] Fadini GP, Sartore S, Agostini C, Avogaro A. Significance of endothelial progenitor cells in subjects with diabetes. Diabetes Care 2007; 30: 1305-1313.

[18] Avogaro A, Fadini GP, Gallo A, Pagnin E, de Kreutzenberg S. Endothelial dysfunction in type 2 diabetes mellitus. Nutr Metab Cardiovasc Dis 2006;16(Suppl. 1):S39-S45

[19] Fadini GP, de Kreutzenberg SV, Coracina A, Baesso I, Agostini C, Tiengo A, et al. Circulating CD34+ cells, metabolic syndrome, and cardiovascular risk. Eur Heart J 2006; 27: 2247-2255.

[20] Fadini GP, Avogaro A. Potential manipulation of endothelial progenitor cells in diabetes and its complications. Diabetes Obes Metab. 2010; 12(7): 570-83.

[21] Asahara T, Murohara T, Sullivan A, et al. Isolation of putative progenitor endothelial cells for angiogenesis. Science. 1997;275:964-967

[22] Lin Y, Weisdorf DJ, Solovey A, Hebbel RP. Origins of circulating endothelial cells and endothelial outgrowth from blood. J Clin Invest. 2000;105:71-77

[23] Hur J, Yoon CH, Kim HS, Choi JH, Kang HJ, Hwang KK. et al. Characterization of two types of endothelial progenitor cells and their different contributions to neovasculogenesis. Arterioscler Thromb Vasc Biol. 2004;24:288-293

[24] Civin CI, Banquerigo ML, Strass LC, Loken MR. Antigenic analysis of hematopoiesis. VI. Flow cytometric characterization of My-10 positive progenitor cells in normal human bone marrow. Exp Hematol. 1987;15:10-17

[25] Peichev M, Naiyer AJ, Pereira D, Zhu Z, Lane WJ, Williams M et al. Expression of VEGFR-2 and $\mathrm{AC} 133$ by circulating human $\mathrm{CD} 34(+)$ cells identifies a population of functional endothelial precursors. Blood. 2000;95:952-958

[26] Yin AH, Miraglia S, Zanjani ED, Almeida-Porada G, Ogawa M, Leary AG et al. AC133, a novel marker for human hematopoietic stem and progenitor cells. Blood. 1997;90:5002-5012

[27] Schmeisser A, Garlichs CD, Zhang H, Eskafi S, Graffy C, Ludwig J, et al. Monocytes coexpress endothelial and macrophagocytic lineage markers and form cord-like structures in Matrigel under angiogenic conditions. Cardiovasc Res. 2001; 49(3): 671-80.

[28] Vaughan EE, O'Brien T. Isolation of circulating angiogenic cells. Methods Mol Biol. 2012; 916:351-6.

[29] Friedrich EB, Walenta K, Scharlau J, Nickenig G, Werner N. CD34-/CD133+/VEGFR-2+ endothelial progenitor cell subpopulation with potent vasoregenerative capacities. Circ Res. 2006; 98: e20-e25

[30] Leri A, Kajstura J. Endothelial progenitor cells: unexpected disclosures. Circ Res. 2005; 97(4):299-301.

[31] Romagnani P, Annunziato F, Liotta F, Lazzeri E, Mazzinghi B, Frosali F. et al. CD14+CD34low cells with stem cell phenotypic and functional features are the major source of circulating endothelial progenitors. Circ Res. 2005; 97: 314-322.

[32] Deschaseaux F, Selmani Z, Falcoz PE, Mersin N, Meneveau N, Penfornis A, et al. Two types of circulating endothelial progenitor cells in patients receiving long term therapy by HMG-CoA reductase inhibitors. Eur J Pharmacol. 2007; 562(1-2): 111-8. 
[33] Rockmaaker MB, Vergeer M, van Zonneveld Aj, Rabelink TJ, Verhaar MC. Endothelial progenitor cells: mainly derived from the monocyte/macrophage containing CD34- but also partly derived from the hematopoetic stem cell containing CD34+ mononuclear population. Circulation. 2003; 108: 150e.

[34] Urbich C, Heeschen C, Aisher A, Dernbach E, Zeiher AM, Dimmeler S. Relevance of monocytic features for neovascularization capacity of circulating endothelial progenitor cells. Circulation. 2003; 108:2511-2516.

[35] Tilling L, Chowienczyk P, Clapp B. Progenitors in motion: mechanisms of mobilization of endothelial progenitor cells. British journal of clinical pharmacology. 2009; 68: 484-92.

[36] Monge M, Massy ZA, van Zonneveld AJ, Rabelink TJ. Endothelial progenitor cells: what are we talking about? Nephrol Ther. 2011; 7(7): 521-5.

[37] Heissig B, Hattori K, Dias S, et al. Recruitment of stem and progenitor cells from the bone marrow niche requires MMP-9 mediated release of kit-ligand. Cell. 2002;109:625-637.

[38] Hattori K, Dias S, Heissig B, Hackett NR, Lyden D, Tateno M, Hicklin DJ, Zhu Z, Witte L, Crystal RG, et al. Vascular endothelial growth factor and angiopoietin-1 stimulate postnatal hematopoiesis by recruitment of vasculogenic and hematopoietic stem cells. J Exp Med. 2001;193:1005-1014

[39] Lataillade JJ, Clay D, Dupuy C, Rigal S, Jasmin C, Bourin P, Le Bousse-Kerdilès MC. Chemokine SDF-1 enhances circulating CD34(+) cell proliferation in synergy with cytokines: possible role in progenitor survival. Blood. 2000; 95(3): 756-68.

[40] Lataillade JJ1, Clay D, Bourin P, Hérodin F, Dupuy C, Jasmin C, Le Bousse-Kerdilès MC. Stromal cell-derived factor 1 regulates primitive hematopoiesis by suppressing apoptosis and by promoting $\mathrm{G}(0) / \mathrm{G}(1)$ transition in $\mathrm{CD} 34(+)$ cells: evidence for an autocrine/paracrine mechanism. Blood. 2002; 99(4): 1117-29.

[41] Kucia M, Jankowski K, Reca R, Wysoczynski M, Bandura L, Allendorf DJ, et al. CXCR4-SDF1 signalling, locomotion, chemotaxis and adhesion. J Mol Histol. 2004; 35(3): 233-45.

[42] Ceradini DJ, Kulkarni AR, Callaghan MJ, Tepper OM, Bastidas N, Kleinman ME. et al. Progenitor cell trafficking is regulated by hypoxic gradients through HIF-1 induction of SDF-1. Nat Med. 2004;10:858-864

[43] Byrne A, Bouchier-Hayes DJ, Harmey JH. Angiogenic and cell survival functions of vascular endothelial growth factor (VEGF) J Cell Mol Med. 2005;9:777-794

[44] Cho HJ, Kim HS, Lee M, Kim DH, Yang HJ, Hur J. et al. Mobilized endothelial progenitor cells by granulocyte-macrophage colony-stimulating factor accelerate reendotheliazation and reduce vascular inflammation after intravascular radiation. Circulation. 2003;108:2918-2925

[45] Fadini GP, Agostini C, Avogaro A. Endothelial progenitor cells and vascular biology in diabetes mellitus: current knowledge and future perspectives. Curr Diabetes Rev. 2005; 1(1): 41-58.

[46] Fadini GP, Sartore S, Albiero M, Baesso I, Murphy E, Menegolo M. et al. Number and function of endothelial progenitor cells as a marker of severity for diabetic vasculopathy. Arterioscler Thromb Vasc Biol 2006; 26:2140-2146

[47] Humpert PM, Neuwirth R, Battista MJ, Voronko O, von Eynatten M, Konrade I. et al. SDF-1 genotype influences insulin-dependent mobilization of adult progenitor cells in type 2 diabetes. Diabetes Care 2005;28:934-936

[48] Kränkel N, Adams V, Linke A, Gielen S, Erbs S, Lenk K, Schuler G, Hambrecht R. Hyperglycemia reduces survival and impairs function of circulating blood-derived progenitor cells. Arterioscler Thromb Vasc Biol. 2005; 25(4): 698-703.

[49] Ye L, Poh KK. Enhancing endothelial progenitor cell for clinical use. World J Stem Cells. 2015; 7(6):894-8.

[50] Vasa M, Fichtlscherer S, Aisher A, Adler K, Urbich C, Martin H. et al. Number and migratory activity of circulating endothelial progenitor cells inversely correlate with risk factors for coronary artery disease. Circ Res. 2001; 89: e1-e7.

[51] Berezin A, Samura T, Kremzer A, Berezina T, Martovitskaya Y, Gromenko E. An association of serum vistafin level and number of circulating endothelial progenitor cells in type 2 diabetes mellitus patients. Diabetes \& Metabolic Syndrome: Clinical Research \& Reviews. 2016 [epub ahead of print] doi:10.1016/j.dsx.2016.06.008 
[52] Werner N, Kosiol S, Schiegl T, Ahlers P, Walenta K, Link A, et al. Circulating endothelial progenitor cells and cardiovascular outcomes. N Engl J Med. 2005; 353(10):999-1007.

[53] Schmidt-Lucke C, Rössig L, Fichtlscherer S, Vasa M, Britten M, Kämper U, et al. Reduced number of circulating endothelial progenitor cells predicts future cardiovascular events: proof of concept for the clinical importance of endogenous vascular repair. Circulation. 2005; 111(22): 2981-7.

[54] Fadini GP, Miorin M, Facco M, Bonamico S, Baesso I, Grego F, et al. Circulating endothelial progenitor cells are reduced in peripheral vascular complications of type 2 diabetes mellitus. $\mathbf{J}$ Am Coll Cardiol. 2005; 45(9): 1449-57.

[55] Berezin AE, Kremzer AA, Samura TA, Berezina TA, Kruzliak P. Impaired immune phenotype of circulating endothelial-derived microparticles in patients with metabolic syndrome and diabetes mellitus. J Endocrinol Invest. 2015; 38(8): 865-74.

[56] Berezin AE. Diabetes mellitus and cellular replacement therapy: Expected clinical potential and perspectives. World J Diabetes. 2014; 5(6): 777-86.

[57] Sen S, McDonald SP, Coates PT, Bonder CS. Endothelial progenitor cells: novel biomarker and promising cell therapy for cardiovascular disease. Clin Sci (Lond). 2011; 120(7): 263-83.

[58] Berezin A, Kremzer A. Analysis of Various Subsets of Circulating Mononuclear Cells in Asymptomatic Coronary Artery Disease. J. Clin. Med. 2013; 2: 32-44.

[59] Lüscher TF. Novel mechanisms of atherosclerosis and cardiovascular repair. Eur Heart J 2016 37: 1709-1711.

[60] Du F, Zhou J, Gong R, Huang X, Pansuria M, Virtue A, et al. Endothelial progenitor cells in atherosclerosis. Front Biosci (Landmark Ed) 2012;17:2327-2349

[61] Lee PS, Poh KK. Endothelial progenitor cells in cardiovascular diseases. World J Stem Cells. 2014;6:355-366

[62] Georgescu A, Alexandru N, Andrei E, Titorencu I, Dragan E, Tarziu C, et al. Circulating microparticles and endothelial progenitor cells in atherosclerosis: pharmacological effects of irbesartan. J Thromb Haemost. 2012; 10: 680-691.

[63] Güven H, Shepherd RM, Bach RG, Capoccia BJ, Link DC. The number of endothelial progenitor cell colonies in the blood is increased in patients with angiographically significant coronary artery disease. J Am Coll Cardiol. 2006;48:1579-1587

[64] Delva P, De Marchi S, Prior M, Degan M, Lechi A, Trettene M, Arosio E. Endothelial progenitor cells in patients with severe peripheral arterial disease. Endothelium. 2008;15:246253

[65] Lee LC, Chen CS, Choong PF, Low A, Tan HC, Poh KK. Time-dependent dynamic mobilization of circulating progenitor cells during percutaneous coronary intervention in diabetics. Int $\mathbf{J}$ Cardiol. 2010;142:199-201

[66] Fadini GP, Sartore S, Baesso I, Lenzi M, Agostini C, Tiengo A. et al. Endothelial progenitor cells and the diabetic paradox. Diabetes Care 2006; 29:714-716.

[67] Makino H, Okada S, Nagumo A, Sugisawa T, Miyamoto Y, Kishimoto I. et al. Decreased circulating CD34+ cells are associated with progression of diabetic nephropathy. Diabet Med 2009;26:171-173

[68] Asnaghi V, Lattanzio R, Mazzolari G, Pastore MR, Ramoni A, Maestroni A, et al. Increased clonogenic potential of circulating endothelial progenitor cells in patients with type 1 diabetes and proliferative retinopathy. Diabetologia 2006; 49: 1109-1111.

[69] Berezin AE. Progenitor endothelial cell dysfunction in heart failure: clinical implication and therapeutic target? Translational Medicine (Sunnyvale). 2016; 6 (3): 176-177. http://dx.doi.org/10.4172/2161-1025.1000176.

[70] Zhang Y, Chen Z, Wang T, Yang J, Li R, Wang S, et al. Treatment of diabetes mellitus-induced erectile dysfunction using endothelial progenitor cells genetically modified with human telomerase reverse transcriptase. Oncotarget. 2016. doi: 10.18632/oncotarget.9909. [Epub ahead of print]

[71] Yu JW, Deng YP, Han X, Ren GF, Cai J, Jiang GJ. Metformin improves the angiogenic functions of endothelial progenitor cells via activating AMPK/eNOS pathway in diabetic mice. Cardiovasc Diabetol. 2016; 15(1): 88. 
[72] Cai JJ, Wen J, Jiang WH, Lin J, Hong Y, Zhu YS. Androgen actions on endothelium functions and cardiovascular diseases. J Geriatr Cardiol. 2016; 13(2): 183-96.

[73] Dauwe D, Pelacho B, Wibowo A, Walravens AS, Verdonck K, Gillijns H, et al. Neovascularization Potential of Blood Outgrowth Endothelial Cells From Patients With Stable Ischemic Heart Failure Is Preserved. Am Heart Assoc. 2016; 5(4). doi:10.1161/JAH A.115.0022 88.

[74] De Ciuceis C, Rossini C, Tincani A, Airò P, Scarsi M, Agabiti-Rosei C, et al. Effect of antihypertensive treatment with lercanidipine on endothelial progenitor cells and inflammation in patients with mild to moderate essential hypertension. Blood Press. 2016:1-7. [Epub ahead of print]

[75] Niederseer D, Steidle-Kloc E, Mayr M, Müller EE, Cadamuro J, Patsch W, et al. Effects of a 12week alpine skiing intervention on endothelial progenitor cells, peripheral arterial tone and endothelial biomarkers in the elderly. Int J Cardiol. 2016; 214: 343-7.

[76] Wu H, Li R, Wei ZH, Zhang XL, Chen JZ, Dai Q, et al. Diabetes-Induced Oxidative Stress in Endothelial Progenitor Cells May Be Sustained by a Positive Feedback Loop Involving High Mobility Group Box-1. Oxid Med Cell Longev. 2016; 2016: 1943918.

[77] Berezin AE. Is the neutrophil extracellular trap-driven microvascular inflammation essential for diabetes vasculopathy? Biomedical Research and Therapy 2016, 3(5): 618-624 doi: 10.7603/s40730-016-0021-9

[78] Chao TH, Chen IC, Li YH, Lee PT, Tseng SY. Plasma Levels of Proprotein Convertase Subtilisin/Kexin Type 9 Are Elevated in Patients With Peripheral Artery Disease and Associated With Metabolic Disorders and Dysfunction in Circulating Progenitor Cells. J Am Heart Assoc. 2016; 5(5). pii: e003497. doi: 10.1161/JAHA.116.003497.

[79] Tesfamariam B. Endothelial Repair and Regeneration Following Intimal Injury. J Cardiovasc Transl Res. 2016; 9(2): 91-101. 